\section{Características de acesso ao preventivo de câncer de colo do útero: três etapas metodológicas da adaptação do instrumento de coleta de informação}

\author{
Characteristics of access to Pap smear: three \\ methodological stages in the adaptation of \\ a data collection instrument
}

Maria Isabel do Nascimento 1,2

Gina Torres Rego Monteiro ${ }^{1}$

\section{Introdução}

\footnotetext{
1 Escola Nacional de Saúde Pública Sergio Arouca,

Fundação Oswaldo Cruz, Rio de Janeiro, Brasil.

2 Hospital Geral de Nova

Iguaçu, Nova Iguaçu, Brasil.

Correspondência M. I. Nascimento Escola Nacional de Saúde Pública Sergio Arouca Fundação Oswaldo Cruz. Rua Mario Miranda 365, Rio de Janeiro, $R J$ 22715-470, Brasil. ysamaria@uol.com.br
}

\begin{abstract}
The article describes the initial steps in the Portuguese-language adaptation of an instrument to measure characteristics of access to cervical cancer prevention. A universalist approach was adopted to assess conceptual, item, and semantic equivalence. The methodology included a literature review and participation by both experts and women representing the general population. Conceptual and item equivalence was established with participation by experts. Semantic equivalence was analyzed in five stages. Two translations into Portuguese and two back-translations into English were performed independently and evaluated by a third researcher from the public health field. The back-translations showed good referential and connotative similarity to the original, and $a$ consensus version was formulated. Twenty-eight women participated in the pretest, eight of whom in the focus group format. The version proved comprehensible, underwent some modifications, and is ready for the complementary stages in the cross-cultural adaptation process.
\end{abstract}

Uterine Cervical Neoplasms; Health Services Accessibility; Questionnaires
Acesso é um conceito complexo e multidimensional 1,2 definido por autores clássicos do tema como o grau de ajuste entre os clientes e o sistema de serviços de saúde 3,4 . Contempla a interação organizacional dos serviços e as características dos(as) usuários(as) descrita nas dimensões de disponibilidade, acessibilidade, adaptabilidade, capacidade de compra e aceitabilidade ${ }^{3}$. Por outro lado, a Organização Pan-Americana da Saúde (OPAS) 5 admite que o acesso seja interpretado como a possibilidade de se obter atenção à saúde quando se necessita e aponta a dificuldade de sua adequada mensuração, levando à concentração de estudos baseados em medidas de utilização.

Numa perspectiva mais recente, acesso vem sendo interpretado como a liberdade de uso de serviços de saúde, factível de mensuração segundo fatores que capturam distintas interações entre o indivíduo e o sistema de saúde, incorporando a idéia de confiança e de força da comunicação e informação 1. Esses autores acataram as idéias desenvolvidas por Penchansky \& Thomas 3 e propuseram um modelo de acesso desenhado com forma da letra "A", inicial dos termos na língua inglesa referentes às três principais dimensões de acesso (availability, affordability, acceptability). Em outras palavras, o modelo toma a forma de uma pirâmide assentada na relação entre fatores do sistema de saúde, individuais e da comunidade, que tem no topo 
o acesso. Os autores argumentam que a informação e a comunicação fortalecem a interação e permitem que os indivíduos façam escolhas, dando um sentido de liberdade de utilização e reduzem a operacionalização de medidas de acesso à avaliação das dimensões de disponibilidade, capacidade de compra e aceitabilidade.

No campo da saúde pública, o controle do câncer de colo de útero constitui-se em desafio superável por um sistema de saúde funcional, com abrangente cobertura da população alvo e acesso satisfatório aos serviços ${ }^{6}$. No Brasil, o planejamento das ações de intervenção e controle desse câncer se desenvolve, especialmente, no plano técnico-assistencial, direcionado para o diagnóstico e tratamento das lesões precursoras e de casos confirmados de doença 7 . O acesso e a utilização de serviços de saúde, como fatores impactantes das ações voltadas para este tipo de câncer, têm sido analisados por meio de inquéritos de abrangência nacional 8,9,10. Nesses estudos, há quesitos focados na utilização de exames, notadamente o teste de Papanicolaou usado para detecção de alterações que precedem à doença invasiva.

O inquérito domiciliar sobre comportamentos de risco e morbidade referida de doenças e agravos não transmissíveis, desenvolvido no período 2002-2003, coordenado pelo Instituto Nacional de Câncer (INCA), buscou, dentre outros objetivos, estimar o percentual de acesso a exames de detecção precoce de câncer de colo de útero e de mama em 15 capitais brasileiras e no Distrito Federal, em mulheres de 25 a 59 anos. O foco foi a realização de pelo menos um exame de Papanicolaou nos últimos três anos anteriores à pesquisa, analisado segundo faixa etária, escolaridade e a natureza da rede de saúde onde foi feito o exame. Os dados desse estudo mostraram que o percentual de mulheres que realizaram o exame nas condições especificadas variou de 73,4\% em João Pessoa (Paraíba) a 92,9\% em Vitória (Espírito Santo) 8 .

O Suplemento Saúde integrante da Pesquisa Nacional por Amostra de Domicílios (PNAD), na versão de 2003, explorou as características do acesso aos serviços preventivos de saúde nas moradoras acima de 24 anos de idade, ao inquirir sobre a última vez que a mulher fez o exame preventivo para o câncer do colo do útero. A análise da proporção de mulheres quanto à realização do exame foi realizada por intervalo de tempo, em quatro categorias: dentro dos últimos três anos, de três a cinco anos, de seis anos ou mais e nunca fez exame preventivo. Os dados foram apresentados segundo estado de residência e faixa etária e permitiram estimar que a cobertura de exame preventivo de colo de útero nos últimos três anos naquelas mulheres foi de $68,7 \% 9$.

Por outro lado, um inquérito conduzido no Brasil de janeiro a setembro de 2003, como parte da Pesquisa Mundial de Saúde, incorporou questões relativas ao acesso, à cobertura e à utilização de serviços de saúde. Dois quesitos dirigidos às mulheres de 18 a 69 anos eram específicos para o controle do câncer de colo do útero. Buscavam verificar a proporção de mulheres que foi submetida a exame ginecológico dentro dos últimos três, quatro ou cinco anos anteriores, há mais de cinco anos ou que nunca fez um exame pélvico; e, se na ocasião do último exame fora coletado material para o teste de Papanicolaou 11. A análise dos dados mostrou que a cobertura de exame ginecológico nos três anos anteriores com realização de teste de Papanicolaou foi de $66 \%$, variando de $54 \%$ a $81 \%$ segundo as condições sócio-econômicas da entrevistada 12 .

Nos Estados Unidos, um sistema de vigilância de fatores de risco comportamentais (Behavioral Risk Factor Surveillance System - BRFSS) coordenado pelo Centers for Disease Control and Prevention (CDC) realiza inquéritos telefônicos anuais, de abrangência nacional, explorando fatores de risco para a saúde de ordem comportamental, o acesso e o uso de serviços de saúde na população com 18 anos de idade ou mais 13. Em termos de saúde da mulher, duas questões investigaram o controle do câncer de colo do útero, na versão de 2002: se a mulher já tinha realizado um teste de Papanicolaou e, para aquelas que responderam positivamente, quando isso ocorreu 14 . Neste estudo, a análise restringiu-se a mulheres com exame realizado dentro dos três anos anteriores à entrevista. Orientados, parcialmente, pelo modelo teórico de utilização de serviços de saúde desenvolvido por Andersen 15, os autores analisaram os dados considerando tanto as variáveis individuais quanto as contextuais. Enfatizaram a importância da variação geográfica no acesso e uso de serviços e analisaram, dentre outras questões, a disponibilidade e proximidade das unidades de saúde em relação ao local de residência.

No âmbito regional, um estudo desenvolvido na Califórnia, nos Estados Unidos, fundamentou-se no conceito de que o acesso está associado a fatores que facilitam a habilidade do indivíduo receber cuidados 16 . Os autores avaliaram o impacto do acesso no rastreio regular do câncer de colo do útero, estabelecido como ter um teste de Papanicolaou dentro de 36 meses da data da entrevista. Examinaram a hipótese de que o acesso e a satisfação poderiam mediar o efeito de fatores sócio-demográficos no uso regular do teste e que poderiam explicar o quanto as desi- 
gualdades étnicas/raciais influenciam no rastreamento regular do câncer de colo do útero. Tais autores divulgaram, junto à publicação dos seus achados, os módulos específicos ao tema, que compõem o questionário usado no estudo.

A disponibilização de questionários, juntamente com publicações científicas, acaba sendo um implemento metodológico para outros estudos e, de fato, um avanço em pesquisas epidemiológicas 17,18 . Verificou-se que o questionário usado por Somkin et al. ${ }^{16}$ contemplava 29 itens, alguns consagrados na literatura de medida de acesso aos serviços de saúde e de seu uso, angariados de diversas fontes, e outros que avaliavam a percepção de satisfação com o cuidado recebido. Os autores reuniram em dois módulos 21 itens categóricos para medir a satisfação com o teste de Papanicolaou e o acesso aos cuidados médicos. Desenvolveram uma escala para medir a satisfação com o processo interpessoal específico à relação médico-paciente e apresentaram algumas medidas psicométricas relativas a esse módulo composto por oito itens.

A inexistência de um instrumento validado para uso no Brasil que contemple as múltiplas dimensões de acesso focado no problema do controle do câncer de colo de útero justificou a opção por esse questionário modular, disponibilizado, livremente, por via eletrônica. Entretanto, antes de se adotar em definitivo um instrumento, deve-se considerar em uma ótica universalista, que os constructos não são os mesmos nas diferentes culturas e que se deve proceder a um exame detalhado de equivalências entre o instrumento original e o vertido 19. Estas concepções justificaram o desenvolvimento do presente estudo que dá passos em direção à qualidade da informação e tem como objetivo relatar as três etapas iniciais implementadas para adaptar para o português o instrumento selecionado para medir características de acesso à prevenção do câncer de colo do útero.

\section{Metodologia}

O presente estudo tem como norte o roteiro proposto por Herdman et al. 19, divulgado no Brasil por alguns autores 20,21,22,23 que assinalam que a adequação de um instrumento de aferição originário de uma determinada cultura demanda por avaliações de seis tipos de equivalências antes de sua utilização em outra. O processo de adaptação transcultural, ora em desenvolvimento, examina a equivalência conceitual, a de itens e a semântica e descreve as contribuições de membros de grupo focal.
Avaliação de equivalências conceitual

\section{e de itens}

A avaliação da equivalência conceitual é o primeiro passo da adaptação transcultural em que se examina se há relevância e correspondência dos conceitos, de modo semelhante, nas duas culturas, originária e alvo. À luz da literatura se contemplou o debate sobre o constructo acesso, suas definições, multidimensionalidade, complexidade e formas de mensuração. Buscou-se conhecer aspectos da construção do instrumento original, ora em adaptação, assim como estudos similares desenvolvidos junto à cultura alvo, a fim de identificar pontos de divergência ou convergência, como assinalado no roteiro adotado 19 .

Fundamentados na experiência e em abrangente revisão bibliográfica, alguns pesquisadores da área de Saúde Coletiva (epidemiologistas antropólogos, planejadores em saúde e médicos especialistas em ginecologia) examinaram a importância e legitimidade do conceito de acesso nas especificidades do controle do câncer de colo do útero. Apresentações em forma de seminário e reunião com especialistas foram os métodos usados para ampliar as discussões e propor soluções às possíveis inconsistências.

A avaliação da equivalência de itens diz respeito ao modo pelo qual os domínios são reproduzidos e é efetuada paralelamente à verificação da equivalência conceitual. No caso, analisam-se os itens segundo sua capacidade de apreender as distintas nuanças, a essência das dimensões e se elas são relevantes em ambas as culturas 19. Começa por uma abrangente revisão da literatura passando pelo julgamento de especialistas e pela opinião de membros da população alvo. Na especificidade do presente estudo, tornou-se importante avaliar a capacidade dos itens abarcarem as múltiplas dimensões de acesso, no contexto preventivo do câncer de colo de útero.

\section{Avaliação da equivalência semântica}

Satisfeitas as apreciações iniciais, a terceira etapa avaliou a transferência de significados entre línguas na expectativa de se obter efeito similar nos respondentes da população alvo. Faz parte do processo a atenção às especificidades de significado referencial e conotativo. $O$ foco é assegurar que o nível de linguagem é adequado para suprir as particularidades da população alvo 19 . É interessante atentar para palavras-chave, expressões e o que cada domínio intenciona cobrir. $\mathrm{O}$ norte do roteiro aponta para o processo como um elemento arte que compreende a habilidade para expressar a mensagem de modo bastante 
próximo ao da população alvo, mas sem perder a essência original.

Inicialmente, procedeu-se à tradução do questionário original. Dois pesquisadores diretamente envolvidos no estudo realizaram traduções do original em inglês para o português, de modo independente, gerando duas traduções. A seguir, foram feitas duas retraduções para o inglês também de modo independente. Colaboradores proficientes na língua inglesa responsabilizaram-se por esta etapa. O sentido, referencial e geral, dos documentos retraduzidos comparados com o original foi avaliado por outro pesquisador da área de saúde coletiva que contribuiu com comentários e sugestões. Nessa etapa de comparação entre os documentos, procurou-se manter oculta qualquer possibilidade de reconhecimento da natureza das versões e do original. A avaliação da semântica referencial foi orientada pela visual analogue scale 24 e focalizou o significado literal dos termos usados na construção de cada item. Foi atribuído a cada item um percentual de $0 \%$ a $100 \%$ conforme o grau de similaridade. Por outro lado, a apreciação do sentido geral buscou garantir a correspondência de conteúdo dos itens inseridos num contexto cultural, na expectativa de que eles produzam impacto similar ao obtido junto ao cenário original. Tendo como base um modelo de qualificação 23, os itens, nessa fase, foram avaliados segundo a classificação "inalterado", "pouco alterado", "muito alterado" e "completamente alterado".

Para avaliar o curso da adaptação transcultural, torna-se oportuno, nessa fase, a programação de reunião com pesquisadores e especialistas. Além da apreciação das versões traduzidas, cabe discutir as sugestões acerca das possíveis modificações e a melhor composição da versão em adaptação, preparada para o pré-teste que, no presente estudo, contou com a apreciação de 28 mulheres da população alvo, algumas reunidas em formato de grupo focal.

\section{Participação do grupo focal}

Membros da população alvo foram consultados em formato de grupo focal. A técnica é apropriada para explorar valores culturais e crenças sobre saúde e doença, fornecendo dados consistentes da visão do público em relação às prioridades de serviços de saúde 25 . Um líder, no caso uma das autoras, conduziu o encontro que reuniu oito mulheres da população alvo. As participantes convidadas eram usuárias da unidade de saúde onde se desenvolve o estudo e não se conheciam. Tinham diferentes idades, todas dentro da faixa recomendada para prevenção do câncer de colo de útero, no Brasil 26. O roteiro do encontro con- templou, além da apresentação das participantes, uma explanação do problema em estudo, admitindo-se que naquele momento estaria sendo examinada a aceitabilidade de um questionário em adaptação. Todas as participantes foram convidadas a opinar sobre os itens componentes e o constructo em avaliação. Enfatizou-se que sua contribuição era importante para superar as imperfeições. Opinaram quanto ao entendimento, parafrasearam os itens e deram sugestões, que foram incorporadas, quando pertinentes à versão em apreciação.

O pré-teste foi complementado com o auxílio de outras vinte mulheres que freqüentavam a unidade de saúde na categoria de acompanhantes de pacientes hospitalizados, permitindo-se, ainda, alguma modificação.

\section{Aspectos éticos}

O estudo foi aprovado pelos Comitês de Ética em Pesquisa do Hospital Geral de Nova Iguaçu (parecer 013/2006) e da Escola Nacional de Saúde Pública Sergio Arouca, Fundação Oswaldo Cruz (parecer 109/09).

\section{Resultados}

\section{Avaliação de equivalências conceitual e de itens}

À luz da literatura e com a contribuição de pesquisadores, especialistas e membros do grupo focal, constatou-se que o acesso é um importante constructo na nossa cultura e resume diferentes interações que afetam o controle do câncer de colo do útero. Engloba múltiplas dimensões que denotam a relação de questões organizacionais do serviço de saúde e do indivíduo. Aspectos de disponibilidade, de capacidade de compra e de aceitabilidade foram identificados e reproduzidos, de alguma maneira, pelos itens componentes do instrumento candidato e aprovado ao processo de adaptação. Aceitou-se que a relação médico-paciente, contemplada em uma escala, poderia sinalizar para a passagem e permanência da mulher dentro do sistema de serviços de saúde, dando indícios de continuidade. Além disso, verificou-se que o módulo que examina a satisfação da mulher com o exame de Papanicolaou incluiu questões relevantes relacionados ao fenômeno em estudo.

Mediante a constatação da equivalência do constructo acesso em ambas as culturas, os pesquisadores optaram pela estrutura original do questionário e estabeleceram a avaliação dos itens componentes. Verificaram que os itens re- 
presentavam importantes domínios de acesso e exploravam questões relevantes do contexto organizacional. Julgaram que havia equivalência de itens e acordaram em função de futuras modificações que deveriam ser implementadas com o intuito de se obter um instrumento culturalmente ajustado e harmonizado à população alvo do estudo principal.

A avaliação da equivalência semântica evoluiu seguindo as etapas do roteiro, obtendo-se traduções bastante equivalentes, embora uma delas tenha mostrado maior similaridade com o original. A comparação dos instrumentos retraduzidos foi realizada por um único avaliador. A análise da semântica referencial mostrou que as versões retraduzidas apresentavam $100 \%$ de similaridade para 17 itens da retradução 1 e 24 itens da retradução 2. Nenhum item obteve avaliação inferior a $80 \%$. Em termos do significado geral, $96 \%$ dos itens foram classificados como inalterados na retradução 1 . Na retradução 2, $83 \%$ dos itens foram classificados como inalterados e $12 \%$ como pouco alterados. O item de número 11 foi originalmente elaborado em formato de enunciado e diz respeito à disponibilidade de seguro de saúde. Foi considerado muito alterado nas duas retraduções porque foi convertido ao formato de uma questão.

As duas traduções contribuíram para a composição de uma versão em português posta à apreciação de especialistas e do grupo focal.

\section{Contribuição de especialistas e do grupo focal}

Os dez primeiros itens avaliam a satisfação da usuária com a realização do último exame preventivo de câncer de colo do útero. De um modo geral, não exigiram grandes modificações. Ajustes pertinentes foram sugeridos apenas para os itens 1 e 5 . O cuidado com o item 1 foi evitar que fosse interpretado como ligado à periodicidade de realização do exame. A sua composição com a expressão "no momento em que precisou dele" pareceu fluir melhor. O item 5 foi modificado em relação ao original dado que tratava de comunicação por idiomas diferentes, questão problemática nos Estados Unidos, mas não no Brasil. A modificação objetivou trazê-lo para o contexto brasileiro e por isso a opção foi contemplar a questão do diálogo em si, as facilidades ou dificuldades para conversar, ou seja, para se fazer entender.

Os itens de 11 a 19 se referem ao acesso aos cuidados médicos e inclui questões consagradas na literatura sobre o assunto. Constatou-se que se referiam aos custos englobados ao processo de cuidados e à probabilidade de utilização dos ser- viços por questão de disponibilidade. Verificouse que outros dois itens exploravam a dificuldade de se obter consulta médica e o tempo de espera no consultório. Acordou-se que eles deveriam ser agregados ao conjunto que examina o acesso.

O propósito dos itens de número 20 até 27 é verificar a maneira como a mulher é atendida no sistema de serviços de saúde. Verificou-se que podem fornecer uma interpretação da interação pessoal ligada à dimensão de aceitabilidade. Com este módulo, espera-se obter uma estimativa da satisfação da usuária com o processo interpessoal, a relação médico-paciente, de um modo global, não relacionada à consulta ou profissional específico. Maior atenção mereceu o item 20 que aborda a concessão de informações sobre os problemas de saúde, com ênfase nos atendimentos médicos passados, não relacionados com as circunstâncias atuais. Por outro lado, considerando que o respeito durante um encontro entre médico e paciente é um dos mais importantes fatores relacionados ao cuidado, procedeu-se a uma revisão minuciosa do assunto com o sentido de identificar melhor a abrangência do item 24 . Acatadas as sugestões de especialistas, o item foi formulado pelo uso do termo "dignidade".

A participação do grupo focal foi um passo preliminar junto à população alvo. Ilustrações, experiências e trajetórias em busca de atenção enriqueceram o debate. As participantes avaliaram os itens sequencialmente e fizeram comentários. O conjunto que trata da "satisfação com o último exame preventivo de câncer de colo de útero" foi bem entendido e aceito pelas participantes. Nenhum item deixou dúvida em relação ao que estava sendo perguntado e querendo captar. Entretanto, para o item 5, que explora "a dificuldade para se fazer entender com alguém da equipe”, teve como sugestão acrescentar a expressão "dialogar com alguém da equipe”, na expectativa de tornar a fala mais completa. Da mesma forma, o conjunto que aborda o acesso aos cuidados médicos mostrou-se de fácil entendimento. Os itens 17 e 19, que exploram o desembolso de dinheiro para realizar o exame preventivo e o de mamas, respectivamente, suscitaram dúvidas em relação a que gastos se referiam. Foi questionado se ali estavam incluídos os gastos ao deixar o domicílio, como, por exemplo, custos para o transporte, interpretado como um importante ônus diante das características dessa população. Os itens da interação médico-paciente também se mostraram de bom entendimento. Em relação ao item 24 que se refere à questão de "dignidade durante a consulta médica", verificou-se que as participantes entenderam "dignidade" como "respeito", "respeito pelo próximo", "respeito pelo semelhante". Vale dizer, um comportamento respeito- 
so que está além das habilidades técnicas. O item 26 foi apreciado e mereceu comentários acalorados. Elas entenderam o sentido de "aceitar as idéias", acharam que era pertinente e ilustraram com observações como "médico se acha dono da verdade" e retruca o que se diz com palavras como: "quer saber mais do que eu?", "o médico aqui sou eu”, "a Senhora também é médica?”.

A avaliação de equivalência semântica encerrou com a entrevista de vinte mulheres da categoria de acompanhantes de doentes hospitalizados cujo resultado reforçou a aceitabilidade prenunciada pelo grupo focal. De um modo geral, as respostas fluíram sem dificuldades, inclusive para a escala que foi aplicada com o auxílio do cartão de respostas alternativas, utilizado para a respondente escolher a opção que melhor se aproximava de sua experiência pessoal. No mais, verificou-se apenas a necessidade de flexibilizar o uso do pronome de tratamento e se optou por deixar em aberto o uso de "você" ou "Senhora", conforme cada situação.

A Tabela 1 sumariza os resultados obtidos com a etapa de avaliação da equivalência semântica, contemplando a similaridade referencial e geral e apresenta a versão-síntese que passou pela apreciação de especialistas e de membros da população alvo.

\section{Discussão}

Em 2002, em torno de 250 mil óbitos por câncer de colo do útero foram registrados no mundo, sendo a maior carga em regiões em desenvolvimento (International Agency for Research on Cancer. CANCERMondial: incidence, mortality and prevalence on world - Globocan 2002 - database: summary table by cancer. http://www-dep. iarc.fr/, acessado em 07/Set/2006). Na América Latina, uma alta proporção de mulheres nunca realizou o teste de Papanicolaou tornando-se as principais vítimas da doença e o foco dos programas de rastreamento 27.

Por outro lado, nos Estados Unidos, alguns autores consideram que as principais barreiras interpostas ao rastreamento desse tipo de câncer são de ordem pessoal e cultural como o lugar de origem/nascimento, proficiência na língua inglesa, o grau de aculturação e a relação médico-paciente; de ordem sócio-econômica como educação, renda, disponibilidade de seguro de saúde e possibilidade de arcar com custos para cuidar da saúde; e, de ordem institucional como recomendação médica, acesso ao cuidado e fonte regular de assistência ${ }^{28}$. Assinala-se que em cenários onde se oferece cuidados primários, vários aspectos organizacionais se revelam como barreiras para o indivíduo que já entrou no sistema 29. Algumas práticas interferem na continuidade, no mecanismo de oferta de provedores e de consultas, assim como no tempo dispensado para o paciente e denotam uma "competência cultural". A autora enfatiza que essas circunstâncias impõem um corolário de problemas para populações específicas, como as de baixa renda, ficando difícil negociar dentro do sistema de saúde, ultrapassar o bloqueio organizacional, tornando problemático o acesso ao cuidado.

Portanto, múltiplos aspectos interagem e constituem potenciais elementos de investigação, especialmente quanto à capacidade de influenciar o efetivo rastreamento do câncer de colo do útero 30 . Esses autores assinalam que o acesso e a utilização do exame preventivo desse câncer têm sido limitados por diferentes barreiras que perpassam a vida das mulheres e que não se restringem às suas características sócio-demográficas. Sugerem que estudos que se proponham a responder perguntas no tema não têm sentido se desenvolvidos à parte do contexto social onde vivem as mulheres e elaboraram um modelo teórico dos fatores associados ao acesso e à utilização do teste de Papanicolaou. Além dos planos social, institucional/programático e individual, o modelo abarca um plano de interação das mulheres com o sistema de serviços de saúde.

O presente estudo foi desenvolvido com o sentido de implementar as etapas iniciais da adaptação do questionário selecionado que contempla múltiplas medidas de acesso e de satisfação com o teste de Papanicolaou e com a relação médico-paciente. A experiência e a opinião de pesquisadores, especialistas e da população alvo enriqueceram esse processo de validação. Como exemplo, verificou-se que no conteúdo havia alguns indicadores das dimensões clássicas de acesso 1,3 que permitiriam futuras análises abrangendo aspectos de disponibilidade, aceitabilidade e capacidade de compra. Embora haja certa dependência entre as dimensões, estudos recentes apontam que elas são conceitualmente distinguíveis e permitem alguma forma de mensuração 1. Portanto, novos desdobramentos podem emergir da aplicação de técnicas estatísticas de psicometria. Por ora, acredita-se que os módulos de satisfação com o exame, satisfação com o processo interpessoal e de acesso ao cuidado médico responderão pelos melindres característicos da interação da mulher com o sistema de serviços de saúde no contexto dessa pesquisa.

O módulo de satisfação com o último teste de Papanicolaou teve um item modificado para atender às características da população alvo. Diz respeito ao caráter multiétnico (negro, filipino, chinês, latino, branco) da população residente 
Tabela 1

Equivalência semântica: comparação entre as retraduções e o instrumento original sob a perspectiva referencial e conotativa e apresentação da versão-síntese.

\begin{tabular}{|c|c|c|c|c|c|c|c|c|}
\hline Escala & Original & Retradução 1 & R1 (\%) & G1 & Retradução 2 & R2 (\%) & G2 & Versão síntese \\
\hline$P$ & $\begin{array}{l}\text { 1) In getting your last } \\
\text { Papanicolaou test, } \\
\text { were you able to get } \\
\text { an appointment at a } \\
\text { convenient time? }\end{array}$ & $\begin{array}{l}\text { 1) In getting your } \\
\text { last Pap smear test, } \\
\text { were you able to get } \\
\text { an appointment at a } \\
\text { convenient time? }\end{array}$ & 95 & IN & $\begin{array}{l}\text { 1) When you got your } \\
\text { last Papanicolaou } \\
\text { test, were you able to } \\
\text { set an appointment } \\
\text { at a convenient time? }\end{array}$ & 85 & PA & $\begin{array}{c}\text { 1) A Sra/Você } \\
\text { conseguiu fazer seu } \\
\text { último exame no } \\
\text { momento em que } \\
\text { precisou dele? }\end{array}$ \\
\hline$P$ & $\begin{array}{l}\text { 2) If you have to } \\
\text { watch children or } \\
\text { someone under your } \\
\text { care, did you have } \\
\text { any problem finding } \\
\text { someone to watch } \\
\text { them? }\end{array}$ & $\begin{array}{l}\text { 2) If you have to } \\
\text { watch children or } \\
\text { someone under your } \\
\text { care, did you have } \\
\text { any problem finding } \\
\text { someone to watch } \\
\text { them? }\end{array}$ & 100 & IN & $\begin{array}{l}\text { 2) If you have to } \\
\text { watch children or } \\
\text { someone under your } \\
\text { care, did you have } \\
\text { any problem finding } \\
\text { someone to watch } \\
\text { them? }\end{array}$ & 100 & IN & $\begin{array}{l}\text { 2) Se a Sra/Você tem } \\
\text { criança ou alguém } \\
\text { para cuidar, teve } \\
\text { alguma dificuldade } \\
\text { para encontrar } \\
\text { alguém para cuidar } \\
\text { deles, quando foi } \\
\text { fazer o seu último } \\
\text { exame preventivo? }\end{array}$ \\
\hline $\mathrm{P}$ & $\begin{array}{l}\text { 3) Did you have to } \\
\text { wait too long at the } \\
\text { clinic before getting } \\
\text { the Papanicolaou } \\
\text { test? }\end{array}$ & $\begin{array}{l}\text { 3) Did you have to } \\
\text { wait too long at the } \\
\text { clinic before getting } \\
\text { the Pap smear test? }\end{array}$ & 95 & IN & $\begin{array}{l}\text { 3) Did you have to } \\
\text { wait too long at the } \\
\text { clinic before getting } \\
\text { the Papanicolaou } \\
\text { test? }\end{array}$ & 100 & IN & $\begin{array}{l}\text { 3) A Sra/Você precisou } \\
\text { esperar muito tempo } \\
\text { na clínica antes de } \\
\text { fazer o exame? }\end{array}$ \\
\hline $\mathrm{P}$ & $\begin{array}{l}\text { 4) In getting your last } \\
\text { Papanicolaou test, } \\
\text { was anyone on the } \\
\text { staff rude or were } \\
\text { they all friendly? }\end{array}$ & $\begin{array}{l}\text { 4) In getting your last } \\
\text { Pap smear test, was } \\
\text { anyone on the staff } \\
\text { rude or were they all } \\
\text { friendly? }\end{array}$ & 95 & IN & $\begin{array}{l}\text { 4) When you got your } \\
\text { last Papanicolaou } \\
\text { test, were anyone on } \\
\text { the staff rude or were } \\
\text { they all friendly? }\end{array}$ & 85 & PA & $\begin{array}{l}\text { 4) Nesse dia, alguém } \\
\text { da equipe foi } \\
\text { grosseiro com a Sra/ } \\
\text { Você ou todos foram } \\
\text { atenciosos? }\end{array}$ \\
\hline$P$ & $\begin{array}{l}\text { 5) Did you have a } \\
\text { problem with any } \\
\text { of the staff's not } \\
\text { speaking (language } \\
\text { of interview)? }\end{array}$ & $\begin{array}{c}\text { 5) Did you have a } \\
\text { problem with any } \\
\text { of the staff's not } \\
\text { speaking (language } \\
\text { of interview)? }\end{array}$ & 100 & IN & $\begin{array}{l}\text { 5) Did you have a } \\
\text { problem with any of } \\
\text { the staff's who do not } \\
\text { speak? }\end{array}$ & 90 & PA & $\begin{array}{c}\text { 5) Quando fez o } \\
\text { último exame, a Sra/ } \\
\text { Você teve alguma } \\
\text { dificuldade para se } \\
\text { fazer entender, para } \\
\text { dialogar com alguém } \\
\text { da equipe? }\end{array}$ \\
\hline$P$ & $\begin{array}{l}\text { 6) Did you have to fill } \\
\text { out too many forms? }\end{array}$ & $\begin{array}{l}\text { 6) Did you have to fill } \\
\text { out too many forms? }\end{array}$ & 100 & IN & $\begin{array}{l}\text { 6) Did you have to fill } \\
\text { out too many forms? }\end{array}$ & 100 & IN & $\begin{array}{c}\text { 6) A Sra/Você teve } \\
\text { que dar informações } \\
\text { para preencher muitos } \\
\text { papéis? }\end{array}$ \\
\hline$P$ & $\begin{array}{c}\text { 7) Was the } \\
\text { Papanicolaou test } \\
\text { painful? }\end{array}$ & $\begin{array}{c}\text { 7) Was the Pap smear } \\
\text { test painful? }\end{array}$ & 95 & IN & $\begin{array}{c}\text { 7) Was the } \\
\text { Papanicolaou test } \\
\text { painful? }\end{array}$ & 100 & IN & $\begin{array}{l}\text { 7) O exame } \\
\text { preventivo foi } \\
\text { doloroso? }\end{array}$ \\
\hline$P$ & $\begin{array}{c}\text { 8) Did you feel } \\
\text { embarrassed } \\
\text { at having the } \\
\text { Papanicolaou test? }\end{array}$ & $\begin{array}{c}\text { 8) Did you feel } \\
\text { embarrassed at } \\
\text { having the Pap smear } \\
\text { test? }\end{array}$ & 95 & IN & $\begin{array}{l}\text { 8) Did you feel } \\
\text { embarrassed while } \\
\text { undergoing the } \\
\text { Papanicolaou test? }\end{array}$ & 90 & PA & $\begin{array}{c}\text { 8) A Sra/Você se } \\
\text { sentiu envergonhada } \\
\text { durante a realização } \\
\text { do preventivo? }\end{array}$ \\
\hline$P$ & $\begin{array}{l}\text { 9) Were you satisfied } \\
\text { with the way you got } \\
\text { your Papanicolaou } \\
\text { test result? }\end{array}$ & $\begin{array}{l}\text { 9) Were you satisfied } \\
\text { with the way you got } \\
\text { your Pap smear test } \\
\text { result? }\end{array}$ & 95 & IN & $\begin{array}{l}\text { 9) Were you satisfied } \\
\text { with the way you got } \\
\text { your Papanicolaou } \\
\text { test result? }\end{array}$ & 100 & IN & $\begin{array}{l}\text { 9) A Sra/Você ficou } \\
\text { satisfeita com o modo } \\
\text { com que foi entregue } \\
\text { o resultado do } \\
\text { preventivo? }\end{array}$ \\
\hline
\end{tabular}

(continua) 
Tabela 1 (continuação)

\begin{tabular}{|c|c|c|c|c|c|c|c|c|}
\hline Escala & Original & Retradução 1 & R1 (\%) & G1 & Retradução 2 & R2 (\%) & G2 & Versão síntese \\
\hline$P$ & $\begin{array}{l}\text { 10) In general, } \\
\text { how satisfied } \\
\text { were you with that } \\
\text { Papanicolaou test } \\
\text { experience? }\end{array}$ & $\begin{array}{l}\text { 10) In general, how } \\
\text { satisfied were you } \\
\text { with that Pap smear } \\
\text { test experience? }\end{array}$ & 95 & IN & $\begin{array}{l}\text { 10) In general, } \\
\text { how satisfied } \\
\text { were you with that } \\
\text { Papanicolaou test } \\
\text { experience? }\end{array}$ & 100 & IN & $\begin{array}{c}\text { 10) De um modo } \\
\text { geral, como a Sra/ } \\
\text { Você se sentiu com a } \\
\text { experiência de fazer o } \\
\text { seu último preventivo? }\end{array}$ \\
\hline A & $\begin{array}{l}\text { 11) Have health } \\
\text { insurance }\end{array}$ & $\begin{array}{l}\text { 11) Do you have } \\
\text { health insurance? }\end{array}$ & 80 & MA & $\begin{array}{l}\text { 11) Do you have } \\
\text { health insurance? }\end{array}$ & 80 & MA & $\begin{array}{l}\text { 11) A Sra/Você tem } \\
\text { seguro de saúde? }\end{array}$ \\
\hline A & $\begin{array}{l}\text { 12) Is there one } \\
\text { particular place } \\
\text { where you usually go } \\
\text { to see a doctor? }\end{array}$ & $\begin{array}{c}\text { 12) Is there a } \\
\text { particular place } \\
\text { where you usually go } \\
\text { to see a doctor? }\end{array}$ & 95 & IN & $\begin{array}{l}\text { 12) Is there one } \\
\text { particular place } \\
\text { where you usually go } \\
\text { to see a doctor? }\end{array}$ & 100 & IN & $\begin{array}{l}\text { 12) Tem algum lugar } \\
\text { específico que a Sra/ } \\
\text { Você normalmente } \\
\text { procura para ser } \\
\text { atendida por um } \\
\text { médico? }\end{array}$ \\
\hline A & $\begin{array}{l}\text { 13) Is there one } \\
\text { particular doctor that } \\
\text { you usually see when } \\
\text { you need a check- } \\
\text { up? }\end{array}$ & $\begin{array}{l}\text { 13) Is there a } \\
\text { particular doctor you } \\
\text { usually see when you } \\
\text { need a check-up? }\end{array}$ & 90 & IN & $\begin{array}{l}\text { 13) Is there one } \\
\text { particular doctor that } \\
\text { you usually see when } \\
\text { you need a check- } \\
\text { up? }\end{array}$ & 100 & IN & $\begin{array}{c}\text { 13) Tem algum } \\
\text { médico específico } \\
\text { que a Sra/Você } \\
\text { normalmente procura } \\
\text { quando precisa fazer } \\
\text { um exame periódico } \\
\text { (check up)? }\end{array}$ \\
\hline A & $\begin{array}{l}\text { 14) When you go to } \\
\text { the doctor, how much } \\
\text { do you usually pay } \\
\text { for each visit? }\end{array}$ & $\begin{array}{l}\text { 14) When you go to } \\
\text { the doctor, how much } \\
\text { do you usually pay } \\
\text { for each visit? }\end{array}$ & 100 & IN & $\begin{array}{l}\text { 14) When you go to } \\
\text { the doctor, how much } \\
\text { do you usually pay } \\
\text { for each visit? }\end{array}$ & 100 & IN & $\begin{array}{l}\text { 14) Quando a Sra/ } \\
\text { Você vai ao médico, } \\
\text { quanto paga pela } \\
\text { consulta? }\end{array}$ \\
\hline A & $\begin{array}{l}\text { 15) Have you gone to } \\
\text { the doctor for check- } \\
\text { ups in the past } 12 \\
\text { months even when } \\
\text { you were well? }\end{array}$ & $\begin{array}{l}\text { 15) Have you gone to } \\
\text { the doctor for check- } \\
\text { ups in the past } 12 \\
\text { months even when } \\
\text { you were well? }\end{array}$ & 100 & IN & $\begin{array}{l}\text { 15) Have you gone to } \\
\text { the doctor for check- } \\
\text { ups in the past } 12 \\
\text { months even when } \\
\text { you were well? }\end{array}$ & 100 & IN & $\begin{array}{l}\text { 15) Mesmo estando } \\
\text { sentindo-se bem, a } \\
\text { Sra/Você procurou } \\
\text { algum médico nos } \\
\text { últimos } 12 \text { meses } \\
\text { para fazer exame } \\
\text { periódico? }\end{array}$ \\
\hline$A$ & $\begin{array}{l}\text { 16) Do you know } \\
\text { where you would } \\
\text { go if you wanted a } \\
\text { mammogram? }\end{array}$ & $\begin{array}{l}\text { 16) Do you know } \\
\text { where you would } \\
\text { go if you wanted a } \\
\text { mammogram? }\end{array}$ & 100 & IN & $\begin{array}{l}\text { 16) Do you know } \\
\text { where you would } \\
\text { go if you wanted a } \\
\text { mammogram? }\end{array}$ & 100 & IN & $\begin{array}{l}\text { 16) A Sra/Você } \\
\text { sabe que lugar } \\
\text { deveria procurar se } \\
\text { quisesse fazer uma } \\
\text { mamografia? }\end{array}$ \\
\hline A & $\begin{array}{l}\text { 17) Did you pay } \\
\text { with any of your } \\
\text { own money when } \\
\text { you got your last } \\
\text { mammogram? }\end{array}$ & $\begin{array}{l}\text { 17) Did you pay } \\
\text { with any of your } \\
\text { own money when } \\
\text { you got your last } \\
\text { mammogram? }\end{array}$ & 100 & IN & $\begin{array}{l}\text { 17) Did you pay } \\
\text { with any of your } \\
\text { own money when } \\
\text { you got your last } \\
\text { mammogram? }\end{array}$ & 100 & IN & $\begin{array}{l}\text { 17) A Sra/Você gastou } \\
\text { algum dinheiro do } \\
\text { seu bolso quando fez } \\
\text { seu último exame de } \\
\text { mamas? }\end{array}$ \\
\hline$A$ & $\begin{array}{l}\text { 18) Do you know } \\
\text { where you would } \\
\text { go if you wanted a } \\
\text { Papanicolaou test? }\end{array}$ & $\begin{array}{l}\text { 18) Do you know } \\
\text { where you would go } \\
\text { if you wanted a Pap } \\
\text { smear test? }\end{array}$ & 95 & IN & $\begin{array}{l}\text { 18) Do you know } \\
\text { where you would } \\
\text { go if you wanted a } \\
\text { Papanicolaou test? }\end{array}$ & 100 & IN & $\begin{array}{c}\text { 18) A Sra/Você sabe } \\
\text { que lugar deveria } \\
\text { procurar se quisesse } \\
\text { fazer um exame } \\
\text { preventivo de câncer } \\
\text { de colo do útero? }\end{array}$ \\
\hline$A$ & $\begin{array}{l}\text { 19) Did you have to } \\
\text { pay with any of your } \\
\text { own money when } \\
\text { you got your last } \\
\text { Papanicolaou test? }\end{array}$ & $\begin{array}{l}\text { 19) Did you have to } \\
\text { pay with any of your } \\
\text { own money when } \\
\text { you got your last Pap } \\
\text { smear test? }\end{array}$ & 95 & IN & $\begin{array}{l}\text { 19) Did you have to } \\
\text { pay with any of your } \\
\text { own money when } \\
\text { you got your last } \\
\text { Papanicolaou test? }\end{array}$ & 100 & IN & $\begin{array}{l}\text { 19) A Sra/Você gastou } \\
\text { algum dinheiro do } \\
\text { seu bolso quando } \\
\text { fez seu último exame } \\
\text { preventivo do câncer } \\
\text { de colo do útero? }\end{array}$ \\
\hline
\end{tabular}

(continua) 
Tabela 1 (continuação)

\begin{tabular}{|c|c|c|c|c|c|c|c|c|}
\hline Escala & Original & Retradução 1 & R1 (\%) & G1 & Retradução 2 & R2 (\%) & G2 & Versão síntese \\
\hline 1 & $\begin{array}{l}\text { 20) In general, how } \\
\text { often do doctors give } \\
\text { you the information } \\
\text { you need about your } \\
\text { health? }\end{array}$ & $\begin{array}{l}\text { 20) In general, how } \\
\text { often do doctors give } \\
\text { you the information } \\
\text { you need about your } \\
\text { health? }\end{array}$ & 100 & IN & $\begin{array}{l}\text { 20) In general, how } \\
\text { often do doctors give } \\
\text { you the information } \\
\text { you need about your } \\
\text { health? }\end{array}$ & 100 & IN & $\begin{array}{l}\text { 20) Em geral, com que } \\
\text { freqüência os médicos } \\
\text { dão para a Sra/Você } \\
\text { informação que a Sra/ } \\
\text { Você precisa sobre } \\
\text { sua saúde? }\end{array}$ \\
\hline 1 & $\begin{array}{l}\text { 21) How often do } \\
\text { doctors give you } \\
\text { enough time to ask } \\
\text { your questions? }\end{array}$ & $\begin{array}{l}\text { 21) How often do } \\
\text { doctors give you } \\
\text { enough time to ask } \\
\text { your questions? }\end{array}$ & 100 & IN & $\begin{array}{l}\text { 21) How often do } \\
\text { doctors give you } \\
\text { enough time to ask } \\
\text { your questions? }\end{array}$ & 100 & IN & $\begin{array}{l}\text { 21) Com que } \\
\text { freqüência os médicos } \\
\text { dão tempo suficiente } \\
\text { para a Sra/Você fazer } \\
\text { suas perguntas? }\end{array}$ \\
\hline 1 & $\begin{array}{c}\text { 22) How often } \\
\text { do doctors listen } \\
\text { carefully to what you } \\
\text { have to say? }\end{array}$ & $\begin{array}{c}\text { 22) How often } \\
\text { do doctors listen } \\
\text { carefully to what you } \\
\text { have to say? }\end{array}$ & 100 & IN & $\begin{array}{c}\text { 22) How often } \\
\text { do doctors listen } \\
\text { carefully to what you } \\
\text { have to say? }\end{array}$ & 100 & IN & $\begin{array}{c}\text { 22) Com que } \\
\text { freqüência os } \\
\text { médicos escutam com } \\
\text { paciência o que a Sra/ } \\
\text { Você tem a dizer? }\end{array}$ \\
\hline I & $\begin{array}{l}\text { 23) How often do } \\
\text { doctors ask if you } \\
\text { have any questions? }\end{array}$ & $\begin{array}{l}\text { 23) How often do } \\
\text { doctors ask if you } \\
\text { have any questions? }\end{array}$ & 100 & IN & $\begin{array}{l}\text { 23) How often do } \\
\text { doctors ask if you } \\
\text { have any questions? }\end{array}$ & 100 & IN & $\begin{array}{l}\text { 23) Com que } \\
\text { freqüência os médicos } \\
\text { perguntam se a Sra/ } \\
\text { Você tem alguma } \\
\text { dúvida? }\end{array}$ \\
\hline I & $\begin{array}{l}\text { 24) How often do } \\
\text { doctors treat you with } \\
\text { respect? }\end{array}$ & $\begin{array}{l}\text { 24) How often do } \\
\text { doctors treat you with } \\
\text { respect? }\end{array}$ & 100 & IN & $\begin{array}{l}\text { 24) How often do } \\
\text { doctors treat you with } \\
\text { respect? }\end{array}$ & 100 & IN & $\begin{array}{c}\text { 24) Com que } \\
\text { freqüência os médicos } \\
\text { tratam a Sra/Você } \\
\text { com dignidade? (de } \\
\text { maneira respeitosa, } \\
\text { educada, atenciosa, } \\
\text { com privacidade) }\end{array}$ \\
\hline I & $\begin{array}{l}\text { 25) How often do } \\
\text { doctors seem to care } \\
\text { about you? }\end{array}$ & $\begin{array}{l}\text { 25) How often do } \\
\text { doctors seem to care } \\
\text { about you? }\end{array}$ & 100 & IN & $\begin{array}{l}\text { 25) How often do } \\
\text { doctors seem to care } \\
\text { about you? }\end{array}$ & $100 \%$ & IN & $\begin{array}{c}\text { 25) Com que } \\
\text { freqüência os médicos } \\
\text { demonstram interesse } \\
\text { pela Sra/por Você? }\end{array}$ \\
\hline I & $\begin{array}{l}\text { 26) How often do } \\
\text { doctors respect your } \\
\text { ideas about your } \\
\text { health problems? }\end{array}$ & $\begin{array}{l}\text { 26) How often do } \\
\text { doctors respect your } \\
\text { ideas about your } \\
\text { health problems? }\end{array}$ & 100 & IN & $\begin{array}{l}\text { 26) How often do } \\
\text { doctors respect your } \\
\text { ideas about your } \\
\text { health problems? }\end{array}$ & 100 & IN & $\begin{array}{c}\text { 26) Com que } \\
\text { freqüência os médicos } \\
\text { aceitam as idéias que } \\
\text { a Sra/Você tem sobre } \\
\text { seus problemas de } \\
\text { saúde? }\end{array}$ \\
\hline I & $\begin{array}{l}\text { 27) How often do you } \\
\text { feel discriminated } \\
\text { against by doctors? }\end{array}$ & $\begin{array}{l}\text { 27) How often do you } \\
\text { feel discriminated } \\
\text { against by doctors? }\end{array}$ & 100 & IN & $\begin{array}{l}\text { 27) How often do you } \\
\text { feel discriminated } \\
\text { against by doctors? }\end{array}$ & 100 & IN & $\begin{array}{l}\text { 27) Com que } \\
\text { freqüência a Sra/Você } \\
\text { se sente discriminada } \\
\text { por médicos? }\end{array}$ \\
\hline A & $\begin{array}{c}\text { 28) Is it easy or } \\
\text { difficult to get } \\
\text { appointments with } \\
\text { your doctor on short } \\
\text { notice if you are sick? }\end{array}$ & $\begin{array}{c}\text { 28) Is it easy or } \\
\text { difficult to get } \\
\text { appointments with } \\
\text { your doctor on short } \\
\text { notice if you are sick? }\end{array}$ & 100 & IN & $\begin{array}{c}\text { 28) Is it easy or } \\
\text { difficult to get } \\
\text { appointments with } \\
\text { your doctor on short } \\
\text { notice if you are sick? }\end{array}$ & 100 & IN & $\begin{array}{c}\text { 28) É fácil ou difícil } \\
\text { conseguir consulta } \\
\text { rapidamente se a Sra/ } \\
\text { Você estiver doente? }\end{array}$ \\
\hline A & $\begin{array}{l}\text { 29) When you go to } \\
\text { your doctor's office, } \\
\text { about how long do } \\
\text { you usually have to } \\
\text { wait before seeing a } \\
\text { doctor? }\end{array}$ & $\begin{array}{l}\text { 29) When you go to } \\
\text { your doctor's office, } \\
\text { about how long do } \\
\text { you usually have to } \\
\text { wait before seeing a } \\
\text { doctor? }\end{array}$ & 100 & IN & $\begin{array}{l}\text { 29) When you go to } \\
\text { your doctor's office, } \\
\text { about how long do } \\
\text { you usually have to } \\
\text { wait before seeing a } \\
\text { doctor? }\end{array}$ & 100 & IN & $\begin{array}{l}\text { 29) Quando a Sra. } \\
\text { vai a uma consulta } \\
\text { médica, quanto } \\
\text { tempo a Sra. espera } \\
\text { no consultório antes } \\
\text { de ser atendida? }\end{array}$ \\
\hline
\end{tabular}

A: acesso; G1: geral da retradução 1; G2: geral da retradução 2; I: interação; IN: inalterado; MA: muito alterado; P: preventivo; PA: pouco alterado; R1:

referencial da retradução 1; R2: referencial da retradução 2 . 
nos Estados Unidos e aborda a dificuldade de acesso imposta pela comunicação, em razão do nível de proficiência na língua inglesa 16 . O item que explorou este problema, não tinha pertinência no contexto em que esta pesquisa está sendo desenvolvida no Brasil. Foi necessário modificá-lo, abordando a dificuldade para o diálogo, o que pode ocorrer mesmo entre pessoas que falam o mesmo idioma. Em relação à dificuldade de diálogo, foi assinalado no pré-teste que características pessoais, como a timidez, também podem desempenhar um papel negativo quando o problema abordado envolve questões de intimidade.

Por outro lado, vale observar que a coleta de dados foi feita originalmente por telefone, por entrevistadores bilíngües, capacitados para conduzir entrevistas diante de população diversa, cobrindo quatro idiomas (Inglês, Cantonês, Tagalo, Espanhol) 16. Tal fato se torna relevante por causa das sutilezas impostas pelas questões culturais na validade de instrumento de aferição. Enfim, não ficou claro o modo como os autores conduziram esta importante questão, que parece não incorrer em grandes implicações para o processo ora em evolução.

As particularidades etárias da população alvo do estudo principal, com possibilidade de incluir casos de câncer de colo do útero e seus controles em idade adulta com limite superior estabelecido aos 69 anos e sem limite inferior conduziram à modificação do item relativo ao "pagamento para realização de mamografia” do módulo de acesso aos cuidados médicos. Segundo as políticas de controle de câncer de mama no Brasil 31, a mamografia regular deve ser realizada a partir dos 50 anos. Esse fato levou à decisão de substituir "mamografia" por "exame das mamas", aceitando-se, nessa categoria, outros exames (clínico, mamográfico, ultra-sonográfico, histopatológico) e, até agora, não foram percebidos prejuízos ao processo.

A escala de satisfação com a relação interpessoal desenvolvida no cenário americano 16 valorizou questões que são importantes para todos os segmentos da população, mas sobretudo para minorias e grupos que vivem em condições sócio-econômicas desfavoráveis 32 . O conjunto trata da comunicação e do estilo interpessoal específicos à relação médico-paciente, abordando, dentre outros aspectos, a questão do respeito ao paciente. No Brasil, a palavra respeito permite várias interpretações. No processo ora em evolução, discutiu-se sobre o termo mais adequado, que denotasse o que se queria captar com o termo "respeito" usado no estudo original ${ }^{16}$. De acordo com alguns estudos consultados 33,34, o termo incorpora o tratamento respeitoso entre o médico e o paciente e o respeito à intimidade, à privacidade. Para adequar o item que aborda este problema, optou-se por usar o termo "dignidade", sugerido por especialistas, agregando termos alternativos ("de maneira respeitosa", "educada”, "atenciosa", "com privacidade") como complemento na formulação final.

A adaptação em curso não envolveu estruturas semânticas complexas o que favoreceu o processo de tradução-retradução. Os pesquisadores aventaram a possibilidade de reformular alguns itens, com o sentido de torná-los concisos. Contudo, as modificações restringiram-se às questões essenciais que passaram pela apreciação das mulheres componentes do grupo focal. Como membros da comunidade e vizinhas da unidade de saúde, as mulheres do grupo focal deram suas contribuições enriquecidas da experiência de utilizar os serviços de saúde da região. Além de examinar o entendimento dos quesitos, o recurso permitiu o debate de questões captadas como barreiras à prevenção do câncer de colo do útero por outros grupos focais 35. Logo, a participação de um grupo focal constituiu-se em um importante incremento metodológico qualitativo para o presente estudo e serve como sugestão para pesquisas de igual natureza.

A avaliação de equivalência operacional é uma etapa do modelo adotado e deve ser formalmente testada 19. Entretanto, algumas questões operacionais mereceram discussões antecipadas que concorreram com as primeiras etapas do processo. Como assinalado previamente, no estudo original a entrevista deu-se por telefone e a adaptação em curso prevê a realização de entrevista face a face. Constatada a divergência, ponderou-se se, na prática, a mudança poderia prejudicar os estudos subseqüentes. Os pesquisadores tenderam a aceitar a mudança, interpretando-a como um fator facilitador. Há a expectativa de que favoreça o desenvolvimento do trabalho, tendo em vista que o instrumento será, a princípio, aplicado em um cenário onde estarão presentes membros do grupo de pesquisa e as participantes do estudo principal. Contudo, o módulo que investiga a percepção de satisfação com a relação médico-paciente pode impor algum grau de inibição à respondente, visto que à frente de algumas entrevistas estará uma das autoras, que é médica. Por enquanto, não é possível antever prejuízos ao estudo, em função da problemática abordada pelo referido conjunto de itens. O módulo será enunciado com clareza, assinalando-se que ele diz respeito às experiências passadas, à maneira como a mulher tem sido atendida no sistema de serviços de saúde, sem relação com o momento atual ou com profissionais específicos. 
No presente estudo, acata-se a interpretação de acesso e realização do teste de Papanicolaou como ocorrido dentro do prazo de três anos prévios à entrevista e se considera importante investigar aspectos organizacionais e de oferta dos serviços de saúde da região passíveis de intervenção. Nesse sentido, intencionou-se cumprir as três primeiras etapas para garantir a validade do instrumento selecionado para a coleta de informação. O estudo evoluiu agregando contribuições, frutos de experiências individuais que enriqueceram o processo que não está esgota- do. As modificações foram feitas para alcançar o sentido coloquial e poder contar com um instrumento adequado para identificar não só os fatores tradicionalmente ligados ao acesso, mas também outras questões que indiretamente in terferem na capacidade de se obter cuidados de saúde no lugar e momentos certos. A versão prétestada mostrou-se compreensível, no entanto ainda carece da análise de equivalência de mensuração, operacional e funcional, etapas que serão, futuramente, desenvolvidas e irão completar esse processo de adaptação transcultural.

\section{Resumo}

O artigo descreve os passos iniciais da adaptação para o português de um instrumento para medir características de acesso focado no controle do câncer de colo do útero. Para avaliar a equivalência conceitual, a de itens e a semântica, adotou-se a abordagem universalista. Além da revisão bibliográfica, contou-se com a participação de especialistas e de mulheres representantes da população geral. A equivalência conceitual e de itens foi estabelecida com a participação de especialistas. A equivalência semântica evoluiu em cinco etapas. Foram feitas duas traduções para o português e duas retraduções para o inglês de modo independen- te, avaliadas por um terceiro pesquisador da área de saúde coletiva. Verificou-se que as retraduções guardavam boa similaridade referencial e conotativa com o original e se formulou uma versão consensual. Vinte e oito mulheres participaram do pré-teste, sendo oito no formato de grupo focal. A versão se mostrou compreensível, logrou algumas modificações e está apta às etapas complementares ao processo de adaptação transcultural.

Neoplasias do Colo do Útero; Acesso aos Serviços de Saúde; Questionários 


\section{Colaboradores}

M. I. Nascimento e G. T. R. Monteiro participaram conjuntamente de todas as etapas de elaboração desse artigo.

\section{Agradecimentos}

Agradecemos às Professoras Mônica Martins e Inês Echenique Mattos, experts que muito contribuíram para a elaboração desse artigo.

\section{Referências}

1. Thiede M, McIntyre D. Information, communication and equitable access to health care: a conceptual note. Cad Saúde Pública 2008; 24:1168-73.

2. Travassos C, Martins M. Uma revisão sobre os conceitos de acesso e utilização de serviços de saúde. Cad Saúde Publica 2004; 20 Suppl 2:S190-8.

3. Penchansky R, Thomas JW. The concept of access: definition and relationship to consumer satisfaction. Med Care 1981; 19:127-40.

4. Donabedian A. Aspects of medical care administration: specifying requirements for health care. Cambridge: Harvard University Press; 1973.

5. Organización Panamericana de la Salud/Organización Mundial de la Salud. Monitoreo de equidad en el acceso a los servicios básicos de salud: guía metodológica. Washington DC: Organización Panamericana de la Salud/Organización Mundial de la Salud; 2000.

6. World Health Organization/International Agency for Research on Cancer. Cervix cancer screening Lyon: IARC Press; 2005. (IARC Handbooks of Cancer Prevention, 10).
7. Coordenação de Prevenção e Vigilância, Instituto Nacional de Câncer, Secretaria de Atenção à Saúde, Ministério da Saúde. Nomenclatura brasileira para laudos cervicais e condutas preconizadas: recomendações para profissionais de saúde. Rev Bras Ginecol Obstet 2006; 28:486-504.

8. Instituto Nacional de Câncer. Inquérito domiciliar sobre comportamentos de risco e morbidade referida de doenças e agravos não transmissíveis: Brasil, 15 capitais e Distrito Federal, 2002-2003. Rio de Janeiro: Instituto Nacional de Câncer; 2004.

9. Instituto Brasileiro de Geografia e Estatística. Pesquisa Nacional por Amostra de Domicílios: acesso e utilização de serviços de saúde. Rio de Janeiro: Instituto Brasileiro de Geografia e Estatística; 2003.

10. Leal MC, Gama SGN, Frias P, Szwarcwald CL. Healthy lifestyles and access to periodic health exams among Brazilian women. Cad Saúde Pública 2005; 21 Suppl 1:S78-88. 
11. World Health Organization. The World Health Report 2000: reducing risks, promoting healthy life. Geneva: World Health Organization; 2002.

12. Szwarcwald CL, Viacava F, Vasconcelos MTL, Leal MC, Azevedo LO, Queiroz RSB, et al. Pesquisa Mundial de Saúde 2003: o Brasil em números. RADIS Comunicação em Saúde 2004; 23:14-33.

13. Centers for Disease Control and Prevention. Behavioral risk factor surveillance system survey questionnaire. Atlanta: U.S. Department of Health and Human Services, Centers for Disease Control and Prevention; 2002.

14. Coughlin SS, Leadbetter S, Richards T, Sabatino SA. Contextual analysis of breast and cervical cancer screening and factors associated with health care access among United States women, 2002. Soc Sci Med 2008; 66:260-75.

15. Andersen RM. Revisiting the behavioral model and access to medical care: does it matter? J Health Soc Behav 1995; 36:1-10.

16. Somkin CP, McPhee SJ, Nguyen T, Stewart S, Shema SJ, Nguyen B, et al. The effect of access and satisfaction on regular mammogram and Papanicolaou test screening in a multiethnic population. Med Care 2004; 42:914-26.

17. Schilling LM, Kozak K, Lundahl K, Dellavalle RP. Inaccessible novel questionnaires in published medical research: hidden methods, hidden costs. Am J Epidemiol 2006; 164:1141-4.

18. Rose T, Olsen J. Invited commentary: the art of making questionnaires better. Am J Epidemiol 2006; 164:1145-9.

19. Herdman M, Fox-Rushby J, Badia X. A model of equivalence in the cultural adaptation of HRQoL instruments: the universalist approach. Qual Life Res 1998; 7:323-35.

20. Reichenheim ME, Moraes CL. Operacionalização de adaptação transcultural de instrumentos de aferição usados em epidemiologia. Rev Saúde Pública 2007; 41:665-73.

21. Hasselmann MH, Reichenheim ME. Adaptação transcultural da versão em português da Conflict Tactics Form R (CTS-1), usada para aferir violência no casal: equivalências semântica e de mensuração. Cad Saúde Pública 2003; 19:1083-93.

22. Moraes CL, Hasselmann MH, Reichenheim ME. Adaptação transcultural para o português do instrumento "Revised Conflict Tactics Scales (CTS2)" utilizado para identificar violência entre casais. Cad Saúde Pública 2002; 18:163-76.
23. Reichenheim ME, Moraes CL, Hasselmann MH. Equivalência semântica da versão em português do instrumento Abuse Assessment Screen para rastrear a violência contra a mulher grávida. Rev Saúde Pública 2000; 34:610-6.

24. Streiner DL, Norman GR. Health measurement scales: a practical guide to their development and use. Oxford: Oxford University Press; 2008.

25. Bowling A. Research methods in health, investigating health and health services. Buckingham: Open University Press; 1997.

26. Instituto Nacional de Câncer. Viva Mulher: câncer do colo do útero: informações técnico-gerenciais e ações desenvolvidas. Rio de Janeiro: Instituto Nacional de Câncer; 2002.

27. Eluf-Neto J, Nascimento CMR. Cervical cancer in Latin America. Semin Oncol 2001; 28:188-97.

28. Downs LS, Smith JS, Scarinci I, Flowers L, Parham $\mathrm{G}$. The disparity of cervical cancer in diverse populations. Gynecol Oncol 2008; 109(2 Suppl):S22-30.

29. Lurie N. Studying access to care in managed care environments. Health Serv Res 1997; 32:691-701.

30. Pinho AA, França-Junior I. Prevenção do câncer de colo do útero: um modelo teórico para analisar o acesso e a utilização do teste de Papanicolaou. Rev Bras Saúde Matern Infant 2003; 3:95-112.

31. Instituto Nacional de Câncer. Estimativas 2008: incidência de câncer no Brasil. Rio de Janeiro: Instituto Nacional de Câncer; 2007.

32. Stewart AL, Nápolez-Springer A, Pérez-Stable EJ, Posner SF, Bindman AB, Pinderhughes HL, et al. Interpersonal processes of care in diverse populations. Milbank Q 1999; 77:305-39.

33. Hsu CC, Chen L, Hu YW, Yip W, Shu CC. The dimensions of responsiveness of a health system: a Taiwanese perspective. BMC Public Health 2006; 6:72.

34. Gouveia GC, Souza WV, Luna CF, Souza-Júnior PRB, Szwarcwald CL. Health care users' satisfaction in Brazil, 2003. Cad Saúde Pública 2005; 21 Suppl:S109-18.

35. Agurto I, Bishop A, Sánchez G, Betancourt Z, Robles S. Perceived barriers and benefits to cervical cancer screening in Latin America. Prev Med 2004; 39:91-8.

Recebido em 02/Out/2009

Aprovado em 16/Abr/2010 